\title{
Toward a Structural Model of Organizational-level Institutional Pluralism and Logic Interconnectedness
}

\author{
Jancsary, Dennis; Meyer, Renate E; Höllerer, Markus A.; Barberio, Vitaliano
}

\author{
Document Version \\ Accepted author manuscript \\ Published in: \\ Organization Science \\ DOI: \\ 10.1287/orsc.2017.1160 \\ Publication date: \\ 2017 \\ License \\ Unspecified
}

Citation for published version (APA):

Jancsary, D., Meyer, R. E., Höllerer, M. A., \& Barberio, V. (2017). Toward a Structural Model of Organizationallevel Institutional Pluralism and Logic Interconnectedness. Organization Science, 28(6), 1150-1167. https://doi.org/10.1287/orsc.2017.1160

Link to publication in CBS Research Portal

\section{General rights}

Copyright and moral rights for the publications made accessible in the public portal are retained by the authors and/or other copyright owners and it is a condition of accessing publications that users recognise and abide by the legal requirements associated with these rights.

\section{Take down policy}

If you believe that this document breaches copyright please contact us (research.lib@cbs.dk) providing details, and we will remove access to the work immediately and investigate your claim. 


\title{
Toward a Structural Model of Organizational-level Institutional Pluralism and Logic Interconnectedness
}

Dennis Jancsary, Renate E Meyer, Markus A. Höllerer, and Vitaliano Barberio

\author{
Journal article (Accepted manuscript)
}

CITE: Jancsary, D., Meyer, R. E., Höllerer, M. A., \& Barberio, V. (2017). Toward a Structural Model of Organizational-Ievel Institutional Pluralism and Logic Interconnectedness. Organization Science, 286), 11501167. 001: 10.1287/orsc.2017.1160

DOI: 10.1287/orsc.2017.1160

Uploaded to Research@CBS: December २०18 


\title{
TOWARDS A STRUCTURAL MODEL OF ORGANIZATIONAL-LEVEL INSTITUTIONAL PLURALISM AND LOGIC INTERCONNECTEDNESS
}

\author{
Dennis Jancsary, WU Vienna \\ dennis.jancsary@wu.ac.at \\ Renate E. Meyer, WU Vienna \& Copenhagen Business School \\ renate.meyer@wu.ac.at \\ Markus A. Höllerer, WU Vienna \& UNSW Sydney Business School \\ markus.hoellerer@wu.ac.at
}

Vitaliano Barberio, WU Vienna

vitaliano.barberio@wu.ac.at

Keywords: Institutional pluralism; constellation of logics; structure of logics; role identities; microfoundations; semantic network analysis; block modeling

Acknowledgements: The authors gratefully acknowledge financial support from the Austrian Science Fund (FWF): I 635-G17. Dennis Jancsary, Renate Meyer, and Markus Höllerer wish to thank SCANCOR for providing an excellent working environment during their sabbaticals. Dennis Jancsary also thanks the Weatherhead Center for International Affairs at Harvard University for its support. We are indebted to our editor and the three anonymous reviewers for their in-depth engagement with our ideas and their valuable suggestions. 


\section{TOWARDS A STRUCTURAL MODEL OF ORGANIZATIONAL-LEVEL INSTITUTIONAL PLURALISM AND LOGIC INTERCONNECTEDNESS}

In this article, we develop a structural model for studying how constellations of multiple institutional logics are instantiated at the organizational level. Conceptually, we complement an institutional logics perspective with structural interactionism and network theory and model a constellation as a nexus of organizational role identities and counter roles. The structure of such a nexus reveals degrees of differentiation and interconnectedness between logics as well as distinct interfaces. We validate and further develop our model through qualitative content analysis and semantic network analytical methods applied to the website of a large organization. Our study contributes to recent literature on institutional pluralism by further specifying the structural aspects of constellations of logics and different types of institutional pluralism (monolithic, fragmented, and modular). Specifically, we show how systems of role categories enable the identification of logics, and how multivocal roles create interfaces between them. We propose logic permeability as a structural attribute of a logic to describe the totality of interfaces it entertains with other logics within a constellation.

Keywords: Institutional pluralism; constellation of logics; structure of logics; role identities; microfoundations; semantic network analysis; block modeling

\section{INTRODUCTION}

In this article, we propose a structural approach to studying institutional pluralism and the constellations of multiple institutional logics at the organizational level through systems of role categories. Institutional logics provide "frames of reference that condition actors' choices for sensemaking, the vocabulary they use to motivate action, and their sense of self and identity" (Thornton, Ocasio, \& Lounsbury, 2012: 2). Organizations commonly operate under conditions of institutional pluralism (e.g., Kraatz \& Block, 2008; Thornton et al., 2012), meaning that they reside at the intersection of multiple institutional logics and must attend to varied, and potentially conflicting, demands from constituencies. Accordingly, they partake in several discourses, and are themselves members of many social categories. The existence of multiple logics is established in literature. Nonetheless, current research rarely moves beyond dyads and often over-emphasizes the conflictual aspects of pluralism.

Multiple logics are not independent of each other, but form specific 'constellations' (e.g., Goodrick \& Reay, 2011). The organizational challenges for dealing with such constellations depend on the relationship between the logics, i.e. whether they are conflicting, complementary, co-existing, etc. 
(e.g., Greenwood, Raynard, Kodeih, Micelotta, \& Lounsbury, 2011; Meyer \& Höllerer, 2010). While research has begun to conceptually explore different dimensions of relationships between logics (e.g., Besharov \& Smith, 2014; Raynard, 2016), more work is needed regarding the structural aspects of whole constellations of logics, the question of whether and how logics are interconnected and overlap, and how interfaces between them can be identified and analyzed.

In order to address these questions, we build on a bottom-up approach. Literature on the microfoundations of multiple institutions (e.g., Powell \& Colyvas, 2008; Thornton et al., 2012) has highlighted the role of identities and practices as ways for organizations to combine elements from different logics (e.g., Kodeih \& Greenwood, 2014; Kraatz \& Block, 2008). However, there is little knowledge on how identities are related to constellations of multiple logics and, with some notable exceptions (e.g., Ocasio, Lowenstein, \& Nigam, 2015), about the structural aspects of this relationship. We therefore aim at developing more systematic insights into the structure of institutional pluralism, the interfaces between logics, as well as the relation between identities and logics.

In a nutshell, we argue that, at the organizational level, constellations of logics emerge bottom-up from role identities and counter roles, and suggest that the structural features of whole constellations can be studied as patterns of role categories. We develop a conceptual model which connects literature on institutional logics (e.g., Thornton et al. 2012) and pluralism (e.g., Kraatz \& Block, 2008) to a structural interactionist understanding of role identities (e.g., Burke \& Stets, 2009; Stryker, 1980, 2008; Stryker \& Burke, 2000), and network analysis (e.g., Mohr \& Guerra-Pearson, 2010). First, building on these sources, we understand role identities as social categories constituted in role identity-practice-counter role 'triplets' (Franzosi, 2010). Second, we argue that such triplets form a patterned 'nexus' of role identities (e.g., Burke \& Stets, 2009). Finally, building on Ocasio, Loewenstein, \& Nigam (2015), we suggest that such a nexus orders role identities as systems, and the underlying category conventions tie clusters within the nexus to institutional logics, thereby giving rise to different forms of institutional pluralism.

We validate and further develop these ideas by translating our conceptual model into qualitative content and semantic network analyses applied to a large organization. By retrieving triplets from its 
website, we identify the multiple role identities and counter-roles the organization instantiates. We then reconstruct the nexus of role identities as a network of role categories and interpret clusters within the network as a constellation of organizational-level logics. By exploring the structural dimensions of network and clusters further, we refine our model and provide novel insights into structural patterns of institutional pluralism and interfaces between logics.

First, our manuscript extends existing insights into the structure of pluralism by showing how constellations of logics may assume varying degrees of differentiation and interconnectedness, thereby giving shape to different forms of pluralism (monolithic, fragmented, and modular) with varying potential for institutional complexity and hybridity. Second, we contribute to the micro-foundations of institutional logics by providing insights into the relation between 'multivocal' role categories and constellations of logics. Third, we suggest that logic permeability as a central attribute helps further explore the overlaps and interfaces between logics within modular forms of pluralism. Finally, our mixed-method approach, combining qualitative content analysis with semantic network analysis, provides an innovative and more rigorous approach to capturing constellations of institutional logics and their structural aspects in a bottom-up manner.

This article proceeds as follows: In the next section we set the conceptual stage by reviewing existing literature on the relationships between multiple institutional logics and the micro-foundations of institutional pluralism. From this, we develop and present our own structural model. We then introduce our case and provide key information on empirical design, data, and methods of analysis. After presenting our findings, we discuss insights into forms of pluralism, interfaces between logics and logic permeability, and highlight conceptual contributions and implications for existing theory in greater detail.

\section{INSTITUTIONAL PLURALISM AND ROLE IDENTITIES}

The aim of this article is to extend insights into the structural properties of whole constellations of institutional logics at the organizational level. We start from existing ideas on the relationship of multiple logics and on how pluralism manifests 'on the ground' (e.g., McPherson \& Sauder, 2013). In 
line with other researchers (e.g., Glynn, 2008; Greenwood et al., 2011; Kodeih \& Greenwood, 2014; Thornton et al., 2012), we contend that identity is a crucial vehicle in this respect.

\section{Relationships of multiple institutional logics}

In modern societies, social space is commonly characterized by the co-presence of a multiplicity of institutional logics. Organizations operating across such pluralistic environments must navigate the challenges created by the existence of multiple audiences and their expectations. Multiple institutional logics within a social space are neither independent from each other, nor is their ordering random; rather, it displays a certain pattern. Goodrick \& Reay (2011: 399) call this a 'constellation' of institutional logics, meaning a composition "of items that $[\ldots]$ can be identified as a pattern".

While research on institutional pluralism is a vibrant research area, we have only recently begun to explore these patterns in more detail. Goodrick and Reay (2011: 380) introduce the concept of 'segmentation' which they describe as the idea that some parts of an organization or profession may "reflect attributes from one logic while other parts reflect attributes from different logics". This is possible because logics are 'decomposable' and can be recombined in various ways. Their study suggests that logics may exhibit different degrees of dominance within organizations and professions, and either co-exist peacefully or battle for dominance. Similarly, Meyer and Höllerer (2010) elaborate that the relationship between logics may have different qualities: they may coexist, compete, supersede each other, or settle upon a temporary truce. Waldorff, Reay, and Goodrick (2013) extend such research in a comparative approach, discussing how different relationships between logics within a constellation either constrain or enable actors exposed to them.

Institutional complexity emerges when organizations are confronted with simultaneous and contradictory prescriptions from multiple logics (e.g., Greenwood et al., 2011). The degree of complexity depends on the range of logics that an organization is subjected to, as well as the specificity of these logics. More recent work has proposed further dimensions to describe logic multiplicity. Besharov \& Smith (2014) suggest compatibility and centrality of logics within the 
organization to construct ideal-typical situations leading to divergent levels of conflict. Per such model, the highest degree of conflict is to be expected when logics are incompatible yet core to organizational functioning. The most exhaustive model of logic multiplicity to date stems from Raynard (2016) who identifies logic compatibility, field-level prioritization, and jurisdictional overlap between logics as central elements and suggests a set of distinct 'institutional landscapes' constituted by different combinations of these elements and each with specific consequences for organizations operating in them.

This literature provides important insights into the relationships between multiple institutional logics. It suggests jurisdictional overlap, compatibility, specificity, and centrality as important aspects of this relationship and discusses consequences for organizations. However, it does not further detail the structural patterning of the whole constellation and the different degrees of interconnectedness of logics within a constellation, the micro-foundations of this patterning or interfaces between logics.

\section{Multiple identities as micro-foundations of institutional pluralism}

A micro-foundations approach (e.g., Powell \& Colyvas, 2008) provides insights into the instantiation of institutional logics in the behaviors and interpretations of individual and collective actors. In particular, identities "are fundamentally interrelated with institutional logics" (Thornton et al., 2012: 128) and play an important role in how actors cope with institutional pluralism. Accordingly, existing research on pluralism is highly conducive to exploring identities and practices that are situated at the interfaces between logics.

It has been shown, for example, how actors can temporarily combine elements of logics to exploit commonalities, whilst maintaining the distinction between them (e.g., Smets, Jarzabkowski, Burke, \& Spee, 2015), combine competing logics by selectively coupling some of their elements (e.g., Pache \& Santos, 2013), or imbue integrative activities with aspects of multiple logics to establish more permanent solutions (e.g., Battilana \& Lee, 2014). Conflicting demands of multiple logics can be integrated into hybrid identities (Rao, Monin, \& Durand, 2003; Meyer \& Hammerschmid, 2006) or 
identity 'scripts' (Bévort \& Suddaby, 2016), and are reconciled through identity work (Creed, DeJordy, \& Lok, 2010). Shared identities in hybrid organizations have been found to enhance their survivability (Battilana \& Dorado, 2010). Previous literature has also shown that pluralistic institutional regimes prompt organizations to develop complex systems of multiple identities (e.g., Kraatz \& Block, 2008; Pratt \& Foreman, 2000). Each identity denotes a specific position which may enable or restrict access to specific institutional logics (e.g., McPherson \& Sauder, 2013). Organizations can shift positions in order to enact different logics towards distinct audiences (e.g., Voronov, De Clercq, \& Hinings, 2013).

This literature tells us much about organizing at the interfaces of logics, but often assumes an agentic perspective. It provides little insight into the larger structures of the overall constellation of logics in which such organizing is embedded. Moreover, the relationship between identities and institutional logics is not necessarily exclusive, which means that identities and the related activities are potentially only loosely coupled with logics (Thornton et al., 2012). In order to understand how institutional pluralism unfolds at the organizational level, we need a more holistic picture of the totality of identities that instantiate the whole constellation, their respective position to each other, and their relation to specific logics.

\section{A STRUCTURAL MODEL OF INSTITUTIONAL PLURALISM}

In order to address these gaps in existing literature, we develop a structural model that relates the multiple role identities of an organization to the organizational level constellation of institutional pluralism. Our structural model introduces 'triplets' of role identities, practices, and counter roles, the 'nexus' of role categories, and an understanding of organizational-level institutional pluralism as emerging from patterned systems of role identities. For this, we 'read' the institutional logics perspective in a structural way and tie it, where fruitful, to structural interactionism, and network theory. 


\section{Structural embeddedness of role identities}

Building on the idea that identities constitute positions in social space, we utilize the concept of 'role identity' (e.g., Burke \& Stets, 2009; Stryker, 1980; 2008) which can be understood as a specific form of institutional identity (e.g., Glynn, 2008). A role identity denotes membership in a social category (Greenwood et al., 2011; Meyer \& Hammerschmid, 2006), such as, for instance, 'professor', or 'doctors', and therefore constitutes sets of "expectations attached to positions occupied in networks of relationships" (Stryker \& Burke, 2000: 286). Although originally developed for the individual level, the concept has been fruitfully translated to the organizational level (e.g., Chreim, Williams, \& Hinings, 2007; Kraatz \& Block, 2008; Stryker, 2008; Whetten \& Mackey, 2002).

Berger and Luckmann (1967) point out that the essence of a social role is its inherent reciprocal typification of actor and act which, for them, lies at the core of every institution. We here equate 'typified activities' to practices - "constellations of socially meaningful activity that are relatively coherent and established" (Thornton et al., 2012: 128). The centrality of practices in the definition means that the identity question of 'who we are as an organization' is mirrored in 'what we do (to others)'. Role identities, consequently, are enacted through the performance of specific practices and in relation to counter-roles (i.e., while 'professors' are expected to 'teach' 'students', 'nurses' are expected to 'treat' 'patients'). We propose the concept of recursive categorization to capture the mutually constitutive relationship between social role, counter-role, and related practices.

The institutional logics perspective acknowledges the crucial entanglement of logics, identities and practices. Thornton et al. (2012; see also Glynn, 2008) state that logics become manifested in the ongoing enactment of identities and practices. Friedland, Mohr, Rose, \& Gardinali (2014) contend that institutions are instantiated by what they call 'troikas' of subject-practice-object-relations which reproduce their 'substances'.

As a first element of our conceptual model, we therefore conclude that institutional logics are instantiated in organizations as mutually constitutive 'triplets' of role identity, counter role, and practices. We take such triplets to be the 'building block' of larger logic constellations. 


\section{Nexus of role identities}

A second, equally central element of our conceptual model builds on Mead's (1934) contention that each actor may potentially assume as many role identities as there are social situations and systems of interaction s/he is engaged in. Also, each role identity can be part of triplets with various 'others' (Merton, 1957; see also Ashforth, 2001). When all triplets an organization is involved in are brought together, a structured configuration of role categories emerges. This corresponds to the suggestion by Ocasio et al. (2015) that categories are integrated into systems - rather than independent lists through category conventions. It also reinforces the idea that role identities constitute positions in the institutional order, defined by the practices they prescribe towards others (e.g., Mohr \& GuerraPearson, 2010).

Following Burke and Stets (2009), we call the categorical system encompassing the totality of role identities, practices, and counter-roles enacted by an organization a 'nexus of role identities' and suggest analyzing it with the help of network constructs. Such an approach allows, for instance, for a more systematic assessment of whether multiple role identities constitute little more than "an amalgam of loosely coupled identities" (Gergen, 1968; quoted in Ashforth \& Mael, 1989: 30) or a more integrated entity in the sense of a consistent 'organizational self' (e.g., Kraatz \& Block, 2008; see also Pratt \& Kraatz, 2009; Stryker, 1980). More importantly, however, it provides more detailed insights into the structure of the constellation of logics that emerges from this nexus.

\section{Structure of pluralistic constellations}

Given the close relation between role categories, practices, and logics, we propose that the overall structure the nexus displays and the patterns in which role identities are interconnected manifest the specific organizational-level constellation of institutional logics. This approach is similar to Ocasio et al.'s (2015) conceptualization of category conventions and vocabulary dimensions as building blocks of institutional logics. Essentially, the nexus of role identities is a network of categories which are 
related to each other in meaningful ways. In more detail, as Ocasio et al. (2015) indicate, collections, or systems, of categories can be linked to institutional logics through the way in which they cluster according to their underlying constitutive dimensions. Hence, we focus on how role categories cluster within the nexus (i.e., the modularity of the network) and understand clusters as instantiations of institutional logics on the organizational level.

This firstly allows inferences about the way in which pluralism is differentiated into multiple logics: Differentiation identifies the number and content of the logics instantiated in the constellation. On a basic note, this is an indicator of how many logics are at work, and, therefore the extent of institutional pluralism (e.g., Greenwood et al., 2011). A nexus can take up any form from only one logic (no differentiation and no pluralism) to a high number of logics (highly differentiated and extensive pluralism). Therefore, our model addresses the concern of scholars (e.g., Goodrick \& Reay, 2011; Greenwood et al., 2011) who have criticized that research too often focuses on the comparison of two logics (e.g., incumbent and challenger) when in pluralistic institutional environments more logics may be relevant.

Secondly, the way the clusters are related to each other enables systematic investigations into the interconnectedness, i.e. which logics overlap to what extent, and how interfaces between them are organized. Interfaces are provided by role identities or counter roles that serve as 'brokers' between two or more logics. The intensity with which they do so is variable and ranges from exclusive role categories with links only within one logic, to role categories that interconnect all logics within the constellation. The number and intensity of interfaces between two logics define the overlap between them. Interconnectedness can range from sparse to dense. The more logics are densely connected, the less modular the overall constellation. At the extreme points of the spectrum, 'fragmented' implies that logics are 'free floating' without any overlaps, while 'very densely interconnected' describes a constellation with a high number of links between logics.

Combining differentiation and interconnectedness provides a two-dimensional space to characterize potential forms of pluralism. Figure 1) shows typical forms. 
Insert Figure 1 about here

The monolithic form (A) is characterized by the absence of any differentiation; there are no clusters in the nexus. Such a form manifests itself in social contexts where no institutional pluralism exists, i.e. in organizations that adhere to only one logic.

The fragmented form (B) combines differentiation (i.e., multiple logics) with the absence of any interconnection between clusters. The number of logics can vary between two and a high number, but all logics co-exist without any overlap. The relationship between role categories and logics is exclusive.

Modular forms (C), finally, are differentiated, yet interconnected. Differentiation implies pluralism, and interconnectedness implies interfaces and overlaps between logics provided through role categories which are coupled to several logics simultaneously. Again, the number of logics can vary.

A more systematic look at the overall constellation as well as the interfaces between logics will allow for a more fine-grained analysis and a refinement of this model. We will validate and further develop these arguments with the help of an empirical case.

\section{METHODOLOGY AND DATA}

We employ a mixed-method approach building on both qualitative content analysis and semantic network analysis to explore how the nexus of role categories a large organization - the City of Vienna administration - enacts, helps in identifying the constellation of logics on the organizational level. ${ }^{1}$ In the following we first present the empirical context and data sources. Then, we outline in detail how we qualitatively reconstruct the multiple role identities and counter-roles from the organization's website and, finally, we explicate how the organizational level constellation of logics can be

\footnotetext{
${ }^{1}$ For the sake of clarity of argument, our empirical exploration and analysis is restricted to recipients of the city administration's products and services. Other external stakeholders, such as national and international governmental bodies, but also internal stakeholders such as employees, would obviously add further complexity.
} 
reconstructed from the clusters within the network, and how the patterns and interfaces can be analysed.

\section{Empirical research context}

The City of Vienna administration is an organization of substantial size (as of 2013, it consists of around 80,000 civil servants in core administrative bodies and agencies, and a considerable number of employees in corporatized units owned by the City of Vienna) with a broad range of tasks in diverse areas that include, amongst others, infrastructure, traffic, urban development, housing, education, health, culture, social affairs, tourism, and commerce. A city administration provides an excellent setting to study multiple role identities under conditions of institutional pluralism. In fact, there is a broad consensus among researchers in public administration that public sector organizations take on multiple roles - for instance, as legislator, regulator, service provider, market participant, authority, etc. - that are performed across a variety of institutional spheres. Previous studies have consistently confirmed that such organizations are subjected to institutional pluralism in addition to being affected by different reform paradigms that pervade the public sector (e.g., New Public Management, or New Public Governance) (e.g., Christensen \& Lægreid, 2011; Hyndman, Liguori, Meyer, Polzer, Rota, \& Seiwald, 2014; Liguori, Sicilia, \& Steccolini, 2009; Meyer, Egger-Peitler, Höllerer, \& Hammerschmid, 2014; Pollitt \& Bouckaert, 2011; Schedler \& Ruegg-Stürm, 2013; Vogel, 2012).

\section{Data sources, sampling, and data preparation}

We define the City of Vienna administration as the totality of all organizational units under its direct control (as represented on the city's publicly accessible website, http://www.wien.gv.at). This includes a variety of entities ranging from core administrative bodies to decentralized agencies and activities.

With websites being increasingly a primary vehicle for communication with key audiences (e.g., Powell \& Oberg, 2017; Powell, Oberg, Korff, \& Kloos, 2017), as well as for identity construction 
(e.g., Brown, 2006; Sillince \& Brown, 2009), we expect this medium to document and record relationships between the city and its constituencies.

A focus on organizational discourse has both advantages as well as limitations. Relying on organizational communication, for instance, neither allows for making detailed inferences about intraorganizational processes, nor does it provide evidence about the actual negotiation of roles in specific interactions between the city and its constituencies. However, neither the internal (e.g., processes of identification) nor the interactional (e.g., identity maintenance in face-to-face interaction) aspects of role identities are at the core of our investigation. Rather, we aim at a better understanding of how the structural properties of systems of role categories instantiate the constellation of logics the organization is subjected to. To this end, websites are a helpful data source, since they address a multitude of different audiences, mention a broad variety of roles and counter-roles, and do not allow organizations to eschew pluralism through compartmentalization. While we acknowledge that websites usually provide an impression of socially 'desired' or 'demanded' identities, the organization is not free to make up role identities; they have to be plausible and appropriate, given that they are under the scrutiny of an increasingly critical audience. In this context, it is also noteworthy that the contents of the city's website are produced in a decentralized way by members of the administrative units and not, as may be suspected, by external public relations agencies or a centralized unit.

To create our dataset, we proceeded in several steps. First, we extracted all texts from the website in an automated manner, using a web-crawler. ${ }^{2}$ The crawl yielded over 60,000 individual web pages. Second, from this initial set, we deleted websites offered in foreign languages (i.e., those merely doubling content) and websites that only provided listings of addresses and contacts. This reduced the number of web pages to be used in further steps by almost 50 percent. Third, we deleted texts that lacked an explicit mentioning of constituencies (e.g., citizens, customers, voters, residents, etc.). ${ }^{3}$ For this purpose, we iteratively combined several standard semi-automatic routines such as the

\footnotetext{
${ }^{2} \mathrm{~A}$ web-crawler is a piece of software that automatically extracts information from web pages (the one we used is available at http://www.winwebcrawler.com).

${ }^{3}$ We used the software tool AUTOMAP (http://www.casos.cs.cmu.edu/projects/automap) to transform texts into concept lists.
} 
classification of words according to their part of speech $^{4}$ (noun, verb, adjective, preposition, etc.), or the detection of potential compound words (e.g., dog owners). After this 'cleaning', our final sample consisted of 3,128 texts (i.e., web pages). These texts mostly belong to one of two primary categories: (a) narrative texts that explain what the city has done or plans to do (e.g., citizen participation for particular projects, organization of events, introduction of new rules or programs, etc.); and (b) prescriptive texts informing the public what to expect from the city and how to access particular services (e.g., how to apply for assistance, how to get a new passport, etc.).

\section{Reconstruction of role categories}

The reconstruction of 'triplets' of role identities, counter roles, and practices is the basis for our structural analysis. We first conducted a qualitative content analysis of the remaining web pages and extracted all sentences that communicate relationships, in the sense of an action creating a link between at least one "city actor ${ }^{5}$ and one external actor ${ }^{6}$ (i.e., as semantic triplets; see, for instance, Franzosi, 2010). We then grammatically generalized these sentences into the active voice (e.g., changed "immigrants are supported by the city" into "the city supports immigrants").

Since the city referred to itself in these triplets primarily by its name or the pronoun "we", a conceptually sound procedure is required to reconstruct its role identities indirectly, rather than through explicit self-categorization. Our model suggests that actors classify themselves as occupants of specific social roles by stating how the other is acted upon, and by whom. This stresses reciprocity in the construction of role identities. For every counter-role that is assigned to the other, there is the implicit assumption of at least one reciprocal role identity and a set of practices linking the two. For instance, the category of 'child' evokes 'parent', the category of 'student' evokes 'professor', or 'consumer' evokes 'producer'. Legitimate corresponding practices would be caring, lecturing, and exchange of goods, respectively.

\footnotetext{
${ }^{4} \mathrm{We}$ used the multi-language part of TreeTagger (http://www.cis.uni-muenchen.de/ schmid/tools/treetagger).

5 'City actors' could be either referred to explicitly (e.g., by mentioning the City of Vienna or one of its organizational units) or implicitly (e.g., using "we", or in follow-up sentences).

${ }^{6}$ We only included abstract actor categories (and not, for instance, named people who might represent such categories).
} 
Building on the mutually constitutive relationship between role identity, counter-role, and related practice(s) (recursive categorization) a role identity can be reconstructed indirectly from the actions that an actor performs towards others; more specifically, by reducing semantic triplets to dyads of actions and addressed object actors. Each dyad constitutes the combination of an action taken by the organization and a vis-à-vis for such an action (for example, 'to support' $\rightarrow$ 'immigrants', or 'to consider demands from' $\rightarrow$ 'groups at the periphery of society'). While we aspired to remain as close to the exact wordings as possible, we generalized verbs (and, to a much lesser extent, also actor labels) of similar meaning in a process of constant comparison (see, e.g., Glaser \& Strauss, 1967) and excluded actor labels and actions that only appeared once. We then transformed the list of 670 dyads into a matrix in the form of 36 actions x 37 object actors. Conceptually, this procedure corresponds to depicting the various forms in which the city addresses (action nodes) its constituencies (actor nodes) as a two-mode network (a network with two different types of nodes).

Our next step involved the aggregation of words (actions and object actors) into more abstract social categories (practices and counter-roles). Earlier, we defined role categories as sets of behavioral expectations attached to positions in networks (Stryker \& Burke, 2000: 286). Labels for actors therefore denote one role category if they occupy similar positions in terms of the actions they are subjected to. According to the same principle, practices can be understood as aggregations of actions with similar structural positions towards recipients. The idea of similar positions in networks is usefully captured by the concept of structural equivalence (see for example Boorman \& White, 1976; White, Boorman, \& Breiger, 1976). A comparable approach to identity has been employed by Mohr (e.g., 1994; Mohr \& Neely, 2009) to reconstruct the classification system underlying the status identities of different types of eligible welfare 'clients' based on the treatments they receive, or by Padgett and Ansell (1993) in their analysis of ties between the elite families in Renaissance Florence. We apply the criterion of structural equivalence to our network of actions and actors by using the $\mathrm{CONCOR}^{7}$ algorithm. This algorithm takes the two-mode action-actor matrix (network) as an input

\footnotetext{
${ }^{7}$ We used the algorithm with the interactive splitting procedure as implemented in the UCINET v. 6.207 analytical software (Borgatti, Everett, \& Freeman, 2002). We applied CONCOR to a two-mode adjacency matrix following a generalization as proposed, for instance, by Borgatti and Everett (1992). In this way, such two-mode structural equivalence block modeling is one in which row nodes are only assigned to the same class if they have
} 
and assigns actions and actors to classes or 'blocks' of structurally equivalent entries (nodes). The distribution of nodes and links of the original two-mode matrix among structurally equivalent partitions is called a block model.

Ten action blocks (practices) and ten actor blocks (counter-roles) were generated through this procedure. To identify an appropriate 'label' for each block, we interpreted the block model according to two complementary criteria: (a) characteristics of members within individual blocks, and (b) the system of relationships of members across blocks. Since role identities and practices taken towards counter-roles are conceptualized as mutually constitutive (recursive categorization), we interpreted the practices the city claims to perform (i.e., action blocks) towards particular counter-roles (i.e., actor blocks) as manifestations of distinct role identities, thereby effectively understanding role identities as sets of practices. ${ }^{8}$ The interpretation process was conducted in several interpretive cycles and constantly involved several authors. Table 1 presents a brief description of action blocks denoting the respective role identities of the city administration. Table 2 is dedicated to counter-roles.

Insert Table 1 about here

Insert Table 2 about here

\section{Reconstructing the nexus of role categories and the constellation of logics}

Building on our structural model of institutional pluralism, we propose a semantic network approach to identifying and analyzing the city's nexus of role identities and constellation of logics. We plotted and further analyzed the block model as an 'aggregated' two-mode semantic network that relates

identical columns, and vice versa. In our case this implies for actor blocks that they are treated by the city in the same or in a similar way, and for action blocks that they are commonly directed towards the same kinds of actor.

${ }^{8}$ For instance, our analysis showed that immigrants, humans in general, people with special needs, the poor, the helpless, inhabitants of homes for the elderly, people in need of care, families, and clients are structurally equivalent. We first assessed the labels used. At a first glance, these are all actors in need of support. We then identified the most typical labels within a block (those with the highest frequency in the material). In our example, these were immigrants, humans in general, and people with special needs. Finally, we evaluated the actions that were most prominently linked to these actors. In this particular case, these were to support, to consider, and to enable. Having consolidated all this information, we decided to label this actor block people in need. We proceeded in the same way with action blocks. The block containing to support, to develop, and to enable was labeled the enabling city, since it was most prominently linked to the people in need, but also to the entrusted (the homeless, victims of abuse) and the policy targets (most prominently women and students). 
action blocks (role identities) to actor blocks (counter-roles). To control for different frequencies, we normalized links between the blocks according to the maximum potential linkage between two specific blocks. The strength of a link, thus, is to be understood in relative terms (i.e., standardized between 0 and 1 ).

Since we propose a micro-foundations approach to identifying constellations of institutional logics as structures of role categories, we proceeded bottom-up to identify the logics based on clustering. Clustering within a network implies modularity, i.e. semi-decomposability and the existence of subsystems that are more closely interconnected within than between, and exhibit a limited number of interfaces between each other. The modularity of the overall nexus provides insights into differentiation and interconnectedness. In line with Ocasio et al. (2015) we contend that clustering in such networks can reveal underlying ordering principles that point to specific logics, thus implying that clusters are a useful tool for a bottom up reconstruction of logics. To accomplish this, we looked for cohesive sub-groups - clusters of densely interconnected nodes within the nexus. Given the characteristics of our network of role identities and counter-roles, we used an algorithm (Newman, 2006) that finds community structure in sparsely weighted networks by optimizing the level of modularity of the overall partition ${ }^{9}$ - blocks are clustered together so that connectivity is maximized within clusters and minimized between them (see colored areas in Figure 2).

Insert Figure 2 about here

The constellation can be analyzed building on its differentiation and interconnectedness. The number of clusters specifies differentiation. Our interpretation of which logics the clusters in the nexus instantiate (see findings chapter 1), i.e. the content of the constellation, builds on a 'pattern matching' approach (see, for instance, Reay \& Jones, 2016). First, we reconstructed the underlying 'concerns' (Ocasio et al., 2015) or 'root metaphor' (Thornton et al., 2012) of each logic based on the role identities, counter roles and practices they cluster through qualitative team interpretation. We built on the expertise of all co-authors, as well as their in-depth knowledge of the topic area; any discrepancies

\footnotetext{
${ }^{9}$ The Newman clustering partitions the network in order to optimize its modularity (for technical details, see Newman, 2006).
} 
were resolved through intense discussions. We then matched our own interpretations with the extensive public management literature on the existence and development of institutional pluralism in the public sector (e.g., Christensen \& Lægreid, 2011; Hyndman et al., 2014; Meyer \& Hammerschmid, 2006; Pollitt \& Bouckaert, 2011; Sahlin-Andersson, 2001; Schedler \& Ruegg-Stürm, 2013; Vogel, 2012).

Interconnectedness pertains to how clusters are linked. In a modular network, certain nodes provide interfaces between clusters. The number and intensity of 'brokers', i.e. nodes that link across clusters, determines the extent of overlap. As not all parts of the network are equally densely interconnected, the distribution of interconnectedness across the network reveals which logics overlap and to which extent. Centrality is based on the intensity of linkages between nodes and shapes the cluster's overall position within the network (i.e., central or peripheral).

\section{FINDINGS AND INTERPRETATION}

To begin with, we find that the nexus of role identities is constituted by a single component with four clusters. A first finding, accordingly, is that, in our case, the constellation of logics at the organizational level is modular (type $\mathrm{C}$ in Figure 1): differentiated, yet interconnected. This implies that broker role categories provide interfaces and, hence, overlaps between the logics within the constellation exist. The network-analytical approach we derive from our structural framework enables us to move beyond the simple identification of the existence of overlaps between the logics and grants more detailed insights into differentiation and interconnectedness.

\section{Differentiation: The multiple logics instantiated at the organizational level}

The degree of differentiation is derived from the number of clusters that emerge within a nexus. In our examples, the organizational-level constellation comprises four logics. The colored areas in Figure 2 depict the clusters obtained through the application of the Newman clustering algorithm (see methodology section for details). As outlined above, we interpret the four clusters in our nexus as 
particular organizational-level logics regarding the scope, objectives, and duties of the city, and the public sector more generally. Based on the role categories forming these clusters and against the backdrop of contemporary literature on different rationalities in the public sector (see above), we understand our clusters to be instantiating the following four logics.

The urban governance logic. In the first cluster, the city primarily enacts its 'context shaping', 'activating', and, to a lesser degree, 'regulating' and 'advocating' role identities. Counter-roles encompass categories of actors that inhabit the space of the city and take part in its governance. We identify the city as a 'space to live' (Lebensraum) as the root metaphor (e.g., Thornton et al., 2012) or underlying concern (Ocasio et al, 2015) of this cluster. The city provides infrastructure and regulates this space, but also invites and activates, through local-level democratic procedures and within predefined boundaries, its inhabitants (particularly those addressed as 'local participants') to co-create this space and assume co-responsibility through participation and co-production. The core organizing principle of this cluster seems to be one of collaboration and cooperation. Such ideas have been discussed in the public sector as instantiating a Public/Urban Governance 'paradigm' (e.g., Hyndman et al., 2014; Osborne, 2010; Pollitt \& Bouckaert, 2011; Rhodes, 2007). Public Governance stresses participative, yet regulated, interaction among interdependent constituents 'at eye level', and collaboration as a core coordinating mechanism. We argue that the organizing principles configuring this cluster can be interpreted as a distinct organizational-level instantiation of an urban governance logic. This constitutes a variant of the societal logic of the state, stressing democratic participation as a source of legitimacy (Thornton et al., 2012), more than bureaucratic aspects. The form and 'flavor' that we find in our configuration (the monitoring and regulating component as opposed to a tendency towards network governance) is not unusual for continental European public governance systems where the 'shadow of hierarchy' (e.g., Scharpf, 1997; for Vienna: Brandtner, Höllerer, Meyer, \& Kornberger, 2017) is particularly long.

The state bureaucracy logic. A second cluster shows a rather different picture. Here, the city assumes more direct 'steering/controlling' role identities while at the same time being 'responsive'. Accordingly, counter-roles are characterized primarily as legal subjects (Rechtssubjekte), defined more 
through their formal status, than through their personhood. The root metaphor is that of the city as a 'territorial authority', and the main organizing principle is one of legal rights and obligations, and of compliance. This cluster, the smallest in the nexus in terms of numbers of role categories, is characterized by a strongly legalistic vocabulary and associated practices. Interactions are of a decidedly formal kind. Such vocabularies and categories reinforce the idea of a city ordering and administering the lives of its subjects by direct intervention, while still being responsive to their (collective, rather than individual) needs (see, for instance, the specific vocabulary of the "public administration' discourse in Hyndman et al., 2014). We suggest that the organizing principles underlying this part of the network instantiate a logic of state bureaucracy, i.e. - like the urban governance logic - a variant of the societal institution of the state, which is, however, more focused on its bureaucratic authority rather than democratic legitimation. The specific organizational instantiation (i.e., the strong emphasis of the legalistic component) reflects the Weberian 'Rechtsstaat' that has been identified as being characteristic for public sector organizations in this particular administrative tradition (Meyer \& Hammerschmid, 2006; Pollitt \& Bouckaert 2011).

The new public management logic. A third cluster encompasses role identities of the city that are concerned with 'providing' services and doing so in a customer-friendly way ('servicing'). Combined with the citizens and customers as prominent counter roles, the configuration of this cluster suggests that it is primarily organized by the principle of market transaction, making the root metaphor one of the city as a service provider. The cluster is characterized by roles and practices related to meeting customer needs, providing adequate services, or being accessible and available for potential customers. This exhibits organizing principles that strongly borrow from the societal logic of the market (e.g., focus on transactions, self-interest as normative basis), imported into the public sector through the ideas of New Public Management (NPM; e.g., Hood, 1991; Pollitt \& Bouckaert, 2011). At its core, NPM represents the rationality of the 'quasi-market' and has carried forward the idea of rethinking the citizen as a customer. The variant of the new public management logic we find in our organization - i.e., focus on service provision, quality, and customer satisfaction (as opposed to competition and privatization) - has also been discussed in many studies in the continental European 
context (e.g., Kuhlmann \& Wollmann, 2014; Hammerschmid \& Meyer, 2005; Schedler \& Proeller, 2009) and is particularly reinforced through the long and vehement rejection of neoliberal philosophies by the political and administrative leadership of the City of Vienna. ${ }^{10}$

The paternalistic logic. The fourth and final cluster comprises those role identities of the city that are related to 'enabling' the weaker parts of its citizenry and 'balancing' their needs versus stronger groups. We suggest that this cluster is organized by the principles of solidarity, care, and reconciliation of interests. The root metaphor is that of the city as a supporter of the weak. The role identities assumed in this cluster bear a strong resemblance to the role of a parent in a traditional family. Supporting those who cannot look after themselves, enabling their development towards a more selfsufficient existence, and speaking on their behalf, are all core practices from a perspective based on nurturing, with loyalty and solidarity as core sources of legitimation. We argue that the organizing principles for this cluster resemble a paternalistic organizational-level instantiation of the family logic. Transferred to public sector organizations, it corresponds to ideas of the social mandate of the "welfare state', an idea that is particularly pronounced in Austria (e.g., Tálos, 1998) and especially in Vienna (e.g., Magistratsabteilung 24, 2012). The particular organizational-level variant of this logic materializes in the power claimed by the city administration as 'pater familias' (see, for instance, 'patriarchal domination' as typical source of authority within the family logic in Thornton et al., 2012) and the latent passivity of the recipients.

These logics represent organizational-level variants of four logics that have been found prevalent in the public sector more generally. They are instantiations of three societal logics: market (new public management), family (paternalistic), and two variants of the state (state bureaucratic and urban governance).

\footnotetext{
${ }^{10}$ With the exception of the Ständestaat in the 1930s and during Austria's annexation to Nazi Germany between 1938 and 1945, the City of Vienna has been under social-democratic rule since the end of the Austro-Hungarian Empire (see also the notion of the 'Red Vienna').
} 


\section{Interconnectedness: The relationship between logics in the constellation}

Interconnectedness pertains to the relationships between the logics within the constellation. On a bilateral level, the interfaces and overlaps between the four logics are quite different. Whereas, for example, the overlap between urban governance and new public management is quite extensive (five role categories out of seven in the urban governance logic establish interfaces with three out of five categories from new public management), it is relatively small between urban governance and the paternalistic logic (only two out of seven role categories in the urban governance logic establish interfaces to one out of five categories in the paternalistic logic). The interconnection between state bureaucratic and paternalistic logic is even more sparse: The only interface between them comes from the link between the 'responsive city' and 'policy targets'. Finally, the sparsity of interconnection between urban governance and state bureaucratic logic is particularly striking, as both represent organizational-level variants - democracy and bureaucracy - of the state logic in Thornton et al. (2012). If confirmed in other studies and also on the field and societal level, this may indicate that the state logic - as currently understood at the societal level - is actually more than one logic.

Modularity implies interfaces that hold the nexus together, but does not require all clusters to be connected to each other. On the level of the overall constellation, our case is relatively densely interconnected: All logics have a direct interface with each other provided by one role identity - the 'responsive city' addresses counter roles from all four logics. There are several role categories at the interface of three logics (e.g., 'citizen', 'inhabitant', 'activating city', 'people in need'). In addition, we find few exclusive role categories: the 'enabling city' as well as the 'entrusted' for the paternalistic logic and the 'steering/controlling city' for state bureaucracy. The other two logics have no exclusive role category.

Interfaces between logics can be further qualified by the intensity of brokerage that certain role categories provide. For instance, the 'responsive' city not only acts as a broker between all logics within the constellation of the city, it also establishes more than one link between the state bureaucracy logic and the new public management logic, while the 'balancing' city only connects the paternalistic logic to the new public management logic as one interface. Where role identities and 
counter-roles are sparsely interconnected, i.e. where they are tied to a small number of 'others', and the relative strength of the link is high (see method section), well-defined categories of actors and practices are at work. These areas of distinctiveness indicate relationships that are highly typified, categories that are well-defined, and a vocabulary that is established. In our example, particularly the triplets within the state bureaucratic logic are highly distinct. This is no surprise, as the legalistic Weberian tradition is deeply ingrained within the organization. The upper left part of the network in figure 2 exhibits a high density of links with a relatively low strength resulting from many broker role categories - in our case these are the activating, context-shaping, servicing, or providing city respectively local participants or citizens. Parts of the network where role identities and counter-roles are densely interconnected indicate areas where categories are 'multivocally inscribed' (Ferraro, Etzion, \& Gehman, 2015). Accordingly, such areas of ambiguity in the nexus exhibit a lower level of typicality and engender flexible labeling and vocabularies. Zones of ambiguity between logics (as in our example between new public management and urban governance) point to unsettled boundaries.

Summing up, in our case, the more established 'incumbent logics' of the field - paternalistic and bureaucratic state - are less interconnected than the 'intruders' - urban governance and new public management. Moreover, the interfaces between the two intruders are intense and, hence, the overlap is extensive, while the incumbents are sparsely interconnected. This finding is in line with claims in the public management literature that NPM is built on the sediments of older logics (e.g., Christensen \& Lægreid, 2011; Fleischer \& Jann, 2011; Polzer, Meyer, Höllerer, \& Seiwald, 2016), questioning the stand-alone quality of public governance and new public management (Hyndman et al., 2014; Pollitt \& Bouckaert, 2011).

What our case clearly shows is that while the definition of a 'cluster' demands that nodes are more strongly connected internally than externally, the distribution of interconnectedness within a constellation can be quite uneven. Uneven distribution accounts for the size of overlaps and a logic's centrality or periphery within the constellation. We will use these insights to further theorize about different forms of institutional pluralism at the organizational level and sharpen the structural model presented in the conceptual framework. 


\section{EXTENSION OF MODEL AND DISCUSSION}

In the following, we first 'zoom out' of our empirical case to further develop our classification of different forms of institutional pluralism and discuss implications for institutional complexity and hybrid organizations - two prominent areas in current institutional research. Second, we 'zoom in' into the interfaces between logics in a constellation and elaborate on the relationship between role categories and constellation of logics. Finally, we introduce the concept of logic permeability to assess the overall extent to which a particular logic overlaps with other logics in the constellation.

\section{Forms of organizational-level pluralism}

Our model contributes to the emerging literature on forms of institutional pluralism and complexity (e.g., Besharov \& Smith, 2014; Goodrick \& Reay, 2011; Raynard, 2016). Unlike existing literature in this area, however, we address recent calls to go beyond competitive dyads and provide a more systematic examination of the structure of multiple logics instantiated as configurations of interconnected elements (e.g., Besharov \& Smith, 2014). We extend our typology of potential forms of pluralism (Figure 1) and discuss them again in the light of our findings and with regard to their contribution to existing literature. Specifically, we suggest that these specific forms of pluralism inhere a different potential for institutional complexity and hybridity.

The monolithic form (A), characterized by a complete absence of differentiation (i.e., encompassing only one single logic), can be expected to be empirically rare, since undifferentiated institutional contexts are not the norm in modern societies, except in 'total institutions' (Goffman, 1968). It can also manifest, for example, when organizations decide to adopt a 'dedicated unitary structure' (Raynard, 2016) and ignore all other institutional expectations. Without pluralism, there is no potential for inter-logic complexity (e.g., Greenwood et al., 2011; Thornton et al., 2012), albeit intra-logic complexity (Meyer \& Höllerer, 2016) is not excluded. Organizations that instantiate a monolithic institutional logic are also per definition not hybrid. Our theory development, accordingly, provides 
only insights for the investigation of monolithic forms on the level of the specific triplets it contains and the internal structuring through relationships between role categories. Although not directly related to pluralism and complexity, this may be especially interesting in longitudinal studies that follow the developments of a particular logic.

The fragmented form (B) constitutes a constellation where multiple logics co-exist, but without any overlap between them. With regard to a constellation's micro-foundations, this is due to the fact that no 'brokers' exist, since each role category is exclusively assigned to one logic only. Essentially, such a constellation can be found in completely segregated logics (Thornton et al., 2012), in the case of perfectly compartmentalized communication arenas (on compartmentalization, see, e.g., Kraatz \& Block, 2008; Pache \& Santos, 2013; Pratt \& Foreman, 2000; Sinha, Daellenbach, \& Bednarek, 2015), or in what Greenwood et al. (2011) called 'structurally differentiated hybrids' ('structural compartmentalization' in Raynard [2016]). Fragmentation does not require a hierarchization of logics within the organization so that all logics can be equally relevant for the organization's functioning (Besharov \& Smith, 2014).

Although there may be complexity between logics on the field or societal level, on the organizational level inter-institutional complexity can only arise when cues as to how to define the situation, i.e. which logic applies, are absent or vague. Such interpretational complexity is particularly grave when both parties in the interaction make incompatible decisions (i.e., enact different logics). Since no broker role categories exist in fragmented pluralism, there is no way for the organization to 'hedge' by enacting a flexible role identity. Padgett \& Ansell (1993) have argued that in order to perform successful 'robust action', attributed interests must be multivocal. This is only possible when role categories are compatible with multiple logics. This is not the case in fragmented pluralism.

Modular forms (C) are characterized by positive degrees of differentiation and interconnectedness. This means that interfaces and overlaps between logics exist. The extent of each overlap is shaped by the number and intensity of interfaces between any two logics in the constellation and the number of logics these brokers connect. Overlaps of logics may have two explanations: On the one hand, it is possible that they are a temporary state during the emergence of a novel zone of meaning (during the 
process of 'segregation' in Thornton et al., 2012), or during institutional change (i.e., one cluster gradually supersedes another; e.g., Thornton \& Ocasio, 1999). On the other hand, modular pluralism can also be permanent. Existing research has suggested that this may be the case with 'blended' hybrids (e.g., Greenwood et al., 2011), when logics are either complementary (e.g., Kraatz \& Block, 2008), or have established a kind of 'truce' (Meyer \& Höllerer, 2010), for instance by establishing a hierarchy of relevance (e.g., Raynard, 2016; Besharov \& Smith, 2014), blending (e.g., Glynn \& Lounsbury, 2005; Meyer \& Hammerschmid, 2006) or sedimenting (e.g., Christensen \& Lægreid, 2011; Polzer et al., 2016).

What our empirical example clearly shows is that interconnectedness not only ranges from sparse to dense, but can also be evenly or unevenly distributed. A logic's position within the network (i.e., central or peripheral) is therefore explained by the number and intensity of broker roles that provide interfaces between logics. Hence, in our example, new public management is placed centrally within the nexus. The paternalistic logic and the state bureaucracy logic contain exclusive role identities and less broker role identities than the other two logics. Consequently, they are positioned more peripherally. It is important to note, however, that centrality in the network does not imply salience in the sense that these role categories are more likely to be enacted most frequently (e.g., Stryker, 1980; Stryker \& Burke 2000) or are the most important for the functioning of the organization (Besharov \& Smith, 2014). Uneven distribution of interconnectedness results in many different possibilities of interfaces, and, hence, in a great variety of distinctive topographies. Figure 3 exemplifies some of them. $^{11}$

Insert Figure 3 about here

Although a modular constellation does not per se imply complexity in the sense of contradictory prescriptions from multiple logics (e.g., Greenwood et al., 2011) - interfaces can equally be complementary or even supportive -, modular pluralism has an inherent potential for institutional complexity. While interpretational complexity is just as possible here as it is in fragmented pluralism,

\footnotetext{
${ }^{11}$ Of course, it is also possible for fragmented and modular forms to be combined.
} 
additional structural forms of institutional complexity may emerge from a lack of clear boundaries between logics. How this complexity unfolds - as aligned complexity, restrained complexity, or as volatile complexity (Raynard, 2016) - will be an empirical question. However, it will be interesting to explore the impact the extent of overlap and the intensity of interfaces have on these types of complexity, as well as on fragility versus durability of hybrid arrangements. In fact, the great variety of potential topographies may account for the vast heterogeneity of empirical findings in current research on the relationships of logics.

\section{Multivocal role categories and institutional logics}

In our bottom-up approach, role categories and their patterning are key to understanding constellations of logics. Our conceptual model relates to Pratt and Foreman's (2000) ideas on the different ways of managing multiple identities. However, we take their ideas one step further and connect them more substantially to Kraatz and Block (2008) by linking multiple identities more systematically to forms of institutional pluralism. We move beyond both approaches by further qualifying relationships between identities and allowing for differentiated forms of interfaces and extents of overlaps within one constellation. This is in line with Thornton et al., (2012; see also Goodrick \& Reay, 2011) who suggest that logics are decomposable and can be recombined in different ways, and with McPherson and Sauder (2013) who specify that certain actor positions are particularly suited to the integration of multiple logics. It also complements Pache and Santos' (2013) claim that the specific elements of logics organizations enact are key to understanding organizing at the interfaces of multiple logics. We extend these arguments by highlighting that not all role categories have the same potential within the constellation and by offering a way to identify which parts or positions can be recombined or integrated.

Role categories that are positioned at the interface of two or more logics are 'multivocal' in the sense that their evocation offers the opportunity to leave open which logic is instantiated. Calling the recipient of a city service a "citizen", therefore, is ambiguous with regard to the role identity of the city and the logic it wishes to instantiate (state bureaucratic, urban governance or new public 
management). Since ambiguity enables discretion (e.g., Greenwood et al., 2011; Meyer \& Höllerer, 2016), evoking multivocal role categories gives organizations more leeway to conform with multiple logics simultaneously, and thereby create spaces for integrated activities (Battilana \& Lee, 2014). Such evocation provides similar advantages as the 'selective coupling' of elements of different logics in Pache and Santos' (2013) study. However, it does not require novel or ad hoc couplings or spontaneous logic 'bridging' as proposed by Smets et al. (2015), since multivocal identities are more enduring components of the relationship between certain organizational-level logics.

With role identities that are positioned at the interface of institutional logics and are therefore only loosely coupled, it is possible to produce what Leifer (1988: 865) has called "local action" that avoids "role claims until there is evidence a claimed role will be conferred". This facilitates hiding which logics are in play at which time and enables "robust action", meaning retreating "behind a shroud of multiple identities" (Padgett \& Ansell, 1993: 1310). Interfaces between logics are therefore more likely to produce institutional innovation (Padgett \& Powell, 2012), but are, at the same time more vulnerable due to their ambiguous nature (e.g., Zuckerman, 1999). As our empirical case shows, not all role categories have the same potential for multivocality; some of them connect all logics and some are exclusive to one specific logic. It is therefore reasonable to assume that such multivocality as an attribute of a particular role identity or counter-role has certain preconditions. We encourage future research to study in more detail under which conditions a role category becomes multivocal.

\section{Logic permeability: A structural characteristic of logics' interfaces}

Based on our findings on interconnectedness, and as outlined above, in modular constellations, the extent of each overlap is shaped by the number and intensity of interfaces, i.e., the broker role categories that link any two logics in the constellation. In addition, every broker can connect a logic to one or more other logics in the constellation (e.g., the 'responsive city' that connects all four logics in our example). The number of all interfaces a particular logic entertains with others relative to the total number of role categories it encompasses, enables an assessment of the logic's distinctness. The distinctness of a logic decreases with (a) its relative share of broker role categories, (b) the number of 
other logics it links to and (c) the intensity and strength of these interfaces. We suggest the concept of logic permeability as structural attribute of logics to capture the totality of interfaces a logic entertains with other logics within a constellation as well as their intensity. In our empirical case, the New Public Management logic is the most permeable logic, since all of its role categories act as brokers, it is connected to all other logics in the constellation, and the intensity of brokerage is high. On the other side of the spectrum, the paternalistic logic is the least permeable in our case, since only three out of five role categories act as brokers, only one of which links to multiple logics. In Figure 3, C2 and C4 can be characterized as more permeable than $\mathrm{C} 1$ and $\mathrm{C} 3$.

Relationships between multiple logics have been primarily characterized based on their incompatibility, jurisdictional overlap, and prioritization/centrality (Besharov \& Smith, 2014; Raynard, 2016). Our structural approach provides complementary, yet so far overlooked, ways to characterize the relationships and interfaces between institutional logics that are based on structural features of the overall constellation. Logic permeability suggests that different degrees of logic compatibility exist. Both Besharov and Smith (2014) and Pache and Santos (2010) understand compatibility as a convergence between logics in terms of goals and means. Compatibility is defined as "the extent to which the instantiations of logics imply consistent and reinforcing organizational actions" (Besharov \& Smith, 2014: 367). Permeability, in contrast, does not require logics to be compatible as a whole, but only within the overlaps, where multiple logics may be evoked through the same practices. Additionally, logic permeability needs to be differentiated from logic specificity, i.e., the degree to which a logic's prescriptions are 'absolute' and preclude adherence to those of another (e.g., Raynard, 2016). The existence of structural overlaps between logics does not necessarily preclude other areas of the logic from being distinct (see 'zones of distinctiveness') with absolute claims to validity.

Permeability means the capacity of a logic to share role categories and practices with other logics. This is based on the conceptual notion that logics are near-decomposable into constituent elements (Thornton et al., 2012), and the relationship between role categories and logics is non-exclusive (e.g., Friedland, 2009). As such constituent elements can be recombined in different ways, multivocal role 
categories allow for the reproduction of multiple logics. Thornton et al. (2012) have defined the scope of a logic according to the number of fields that it can claim relevance for. On the organizational level, the 'scope' of a logic can be understood as the number and diversity of the constituent elements (i.e., role categories) it encompasses. Consequently, logic permeability afforded by modular forms of pluralism means that the scope of each logic within the organization is higher than in fragmented forms (see Figure 1), since triplets at the interfaces between logics can be claimed by either of them.

Although permeability does not imply hybridity, future research might want to study more closely if and how shared elements in the overlaps between logics are potential resources for permanent hybridization (e.g., Battilana \& Lee, 2014) or if the degree of permeability allows for qualified assessments of the institutionalization of a logic.

\section{Limitations and directions for future research}

Like all research, our study has limitations. First, our conceptual model enables us to draw conclusions regarding structural properties of constellations of logics; however, we are not able to discuss how the enactment of the associated role identities plays out in concrete interactions with audiences and constituencies. Second, due to the cross-sectional nature of our data, we have to refrain from theorizing the development of constellations over time. Third, the role identities we inferred from the organization's website are not exhaustive, since we focused on specific types of constituents (for details, see footnote 1). Finally, considering other genres of organizational communication could extend our study by enriching the nexus with additional role identities.

We see particular value in future research which complements our discursive approach with more interactional data about how interfaces between logics are enacted in organizations. It would be highly interesting, for instance, to see how multivocal role identities play out in identity negotiations between administrative units of the city and service recipients. To what degree can such identities be verified (e.g., Burke \& Stets, 2009) flexibly, and what are the consequences for role conflict (e.g., Pratt \& Corley, 2007), role boundaries (e.g., Ashforth, Kreiner, \& Fugate, 2000) and role switching? A 
different line of research could focus on comparative studies of organizations operating in different environments. One specific further avenue of research could be longitudinal studies on how constellations of logics change over time. In particular, our insights could be greatly complemented by research exploring how constellations, as well as overlaps and interfaces between the logics, change when novel logics enter. Finally, our model has been developed on the organizational level; it would also be fruitful to explore societal or field-level constellations. Hence, studies dedicated to the fieldlevel or societal-level would be an excellent addition.

\section{Closing remarks}

In conclusion, our article contributes to research on institutional pluralism by addressing several shortcomings in existing literature. First, we showed how constellations of organizational-level logics can be identified as structures of role categories in a bottom-up way. Second, we presented a model to assess differentiation and interconnectedness of logics within a constellation and suggested a classification of different forms of pluralism that acknowledges these insights. Third, we highlighted that multivocality of role categories is variable - while some are exclusive to certain logics, others create interfaces between them. Fourth, we showed that interfaces and overlaps within a constellation of more than two logics may be distributed unevenly and assume different qualities, thereby giving rise to a great variety of distinctive topographies. We suggest logic permeability as a concept to describe the distinctiveness of logics as variable. Fifth, and finally, we also contributed to the discussion on methodological approaches to the reconstruction of constellations of logics at the organizational level. We suggested a mixed-method approach combining qualitative content analysis and interpretation with semantic network analysis as a useful way of tackling the structural aspects of constellations of logics. Without doubt, questions have remained unsolved; even more will be raised and answered by future research that continues to extend and systematize our knowledge within this field of scholarly inquiry. 


\section{BIBLIOGRAPHY}

Ashforth, B. E. (2001). Role transitions in organizational life: An identity-based perspective. Mahwah, NJ: Lawrence Erlbaum.

Ashforth, B. E., \& Mael, F. A. (1989). Social identity theory and the organization. Academy of Management Review, 14(1), 20-39.

Ashforth, B. E., Kreiner, G. E., \& Fugate, M. (2000). All in a day's work: Boundaries and micro role transitions. Academy of Management Review, 25(3), 472-491.

Battilana, J., \& Dorado, S. (2010). Building sustainable hybrid organizations: The case of commercial microfinance organizations. Academy of Management Journal, 53(6), 1419-1440.

Battilana, J., \& Lee, M. (2014). Advancing research on hybrid organizing - Insights from the study of social enterprises. The Academy of Management Annals, 8(1), 397-441.

Berger, P. L., \& Luckmann, T. (1967). The social construction of reality. A treatise in the sociology of knowledge. New York: Anchor Books.

Besharov, M. L., \& Smith, W. K. (2014). Multiple institutional logics in organizations: Explaining their varied nature and implications. Academy of Management Review, 39(3), 364-381.

Bévort, F., \& Suddaby, R. (2016). Scripting professional identities: how individuals make sense of contradictory institutional logics. Journal of Professions and Organization, 3(1), 17-38.

Boorman, S. A., \& White, H. C. (1976). Social structure from mulitple networks. II. Role structures. American Journal of Sociology, 81(6), 1384-1446.

Borgatti, S. P., \& Everett, M. G. (1992). Regular blockmodels of multiway, multimode matrices. Social Networks, 14(1), 91-120.

Borgatti, S. P., Everett, M. G., \& Freeman, L. C. (2002). UCINET for Windows: Software for Social Network Analysis. Harvard, MA: Analytic Technologies.

Brandtner, C., Höllerer, M. A., Meyer, R. E., \& Kornberger, M. (2017). Enacting governance through strategy: A comparative study on governance configurations in Sydney and Vienna. Urban Studies, 54 (5), 10751091.

Brown, A. D. (2006). A narrative approach to collective identities. Journal of Management Studies, 43(4), 731753.

Burke, P. J., \& Stets, J. E. (2009). Identity Theory. Oxford et al.:Oxford University Press.

Chreim, S., Williams, B. E., \& Hinings, C. R. (2007). Inter-level influences on the reconstruction of professional role identity. Academy of Management Journal, 50(6): 1515-1539.

Christensen, T., \& Lægreid, P. (2011). Complexity and hybrid public administration. theoretical and empirical challenges. Public Organization Review, 11(4), 407-423.

Creed, W. E. D., DeJordy, R., \& Lok, J. (2010). Being the change: Resolving institutional contradiction through identity work. Academy of Management Journal, 53(6), 1336-1364.

Ferraro, F., Etzion, D., \& Gehman, J. (2015). Tackling grand challenges pragmatically: Robust action revisited. Organization Studies, 36(3), 363-390.

Fleischer, J., \& Jann, W. (2011). Shifting discourses, steady learning and sedimentation. The German reform trajectory in the long run. In J.-M. Eymeri-Douzans \& J. Pierre (Eds.), Administrative Reforms and Democratic Governance (pp. 68-79). London and New York: Routledge.

Franzosi, R. P. (2010). Sociology, narrative, and the quality versus quantity debate (Goethe versus Newton): Can computer-assisted story grammars help us understand the rise of Italian fascism (1919-1922)? Theory and Society, 39(6), 593-629.

Friedland, R. (2009). Institution, practice, and ontology: Toward a religious sociology. Research in the Sociology of Organizations, Volume 27, 45-113. Bingley et al.: Emerald.

Friedland, R., Mohr, J., Roose, H., \& Gardinali, P. (2014). The institutional logics of love: Measuring intimate life. Theory and Society, 43(3-4), 333-370.

Gergen, K. J. (1968). Personal consistency and the presentation of self. In C. Gordon \& K. J. Gergen (Eds.), The self in social interaction (Vol. 1, pp. 299-308). New York: Wiley.

Glaser, B. G., \& Strauss, A. L. (1967). The discovery of grounded theory: Strategies for qualitative research. New York: de Gruyter.

Glynn, M. A. (2008). Beyond constraint: How institutions enable identities. In R. Greenwood, C. Oliver, R. Suddaby \& K. Sahlin-Andersson (Eds.), The SAGE handbook of organizational institutionalism (pp. 413-430). Los Angeles et al.: SAGE Publications.

Glynn, M. A., \& Lounsbury, M. (2005). From the critics' corner: Logic blending, discursive change and authenticity in a cultural production system. Journal of Management Studies, 42(5), 1031-1055.

Goffman, E. (1968). Asylums: Essays on the social situation of mental patients and other inmates. New Brunswick \& London: AldineTransaction.

Goodrick, E., \& Reay, T. (2011). Constellations of institutional logics. Work and Occupations, 38(3), 372-416. 
Greenwood, R., Raynard, M., Kodeih, F., Micelotta, E. R., \& Lounsbury, M. (2011). Institutional complexity and organizational responses. The Academy of Management Annals, 5, 317-371.

Hammerschmid, G., \& Meyer, R.E. (2005). New public management in Austria - Local variations of a global theme? Public Administration, 83/3, 709-733.

Hood, C. (1991). A public management for all seasons? Public administration, 69(1), 3-19.

Hyndman, N., Liguori, M., Meyer, R. E., Polzer, T., Rota, S., \& Seiwald, J. (2014). The translation and sedimentation of accounting reforms. A comparison of the UK, Austrian and Italian experiences. Critical Perspectives on Accounting, 25(4-5), 488-408.

Kodeih, F., \& Greenwood, R. (2014). Responding to institutional complexity: The role of identity. Organization Studies, 35(1), 7-39.

Kraatz, M. S., \& Block, E. S. (2008). Organizational implications of institutional pluralism. In R. Greenwood, C. Oliver, R. Suddaby \& K. Sahlin-Andersson (Eds.), The SAGE handbook of organizational institutionalism (pp. 243-275). Los Angeles et al.: SAGE Publications.

Kuhlmann, S., \& Wollmann, H. (2014). An introduction to comparative public administration. Administrative systems and reforms in Europe. Cheltenham et al.: Edward Elgar.

Leifer, E. M. (1988). Interaction preludes to role setting: Exploratory local action. American Sociological Review, 53(6), 865-878.

Liguori, M., Sicilia, M., \& Steccolini, I. (2009). Politicians versus managers: Roles and interactions in accounting cycles. International Journal of Public Sector Management, 22(4), 310-323.

Magistratsabteilung 24 (Ed.). (2012). Wiener Sozialbericht 2012. Wiener Sozialpolitische Schriften, Band 6. Vienna: Magistratsabteilung 24.

McPherson, C. M., \& Sauder, M. (2013). Logics in action. Managing institutional complexity in a drug court. Administrative Science Quarterly, 58(2), 165-196.

Mead, G. H. (1934). Mind, self, and society. Chicago et al.: University of Chicago Press.

Merton, R. K. (1957). The role-set: Problems in sociological theory. The British Journal of Sociology, 8(2), 106120.

Meyer, R. E., Egger-Peitler, I., Höllerer, M. A., \& Hammerschmid, G. (2014). Of bureaucrats and passionate public managers: Institutional logics, executive identities, and public service motivation. Public Administration, 92(4), 861-885.

Meyer, R. E., \& Hammerschmid, G. (2006). Changing institutional logics and executive identities. A managerial challenge to public administration in Austria. American Behavioral Scientist, 49(7), 1000-1014.

Meyer, R. E., \& Höllerer, M. A. (2010). Meaning structures in a contested issue field: A topographic map of shareholder value in Austria. Academy of Management Journal, 53(6), 1241-1262.

Meyer, R. E., \& Höllerer, M. A. (2016). Laying a smoke screen: Ambiguity and neutralization as strategic responses to intra-institutional complexity. Strategic Organization, 14/4, 373-406.

Mohr, J. W. (1994). Soldiers, mothers, tramps and others: Discourse roles in the 1907 New York City charity directory. Poetics, 22(4), 327-357.

Mohr, J. W., \& Guerra-Pearson, F. (2010). The duality of niche and form: The differentiation of institutional space in New York City, 1888-1917. Research in the Sociology of Organizations, Volume 31, 321-368. Bingley et al.: Emerald.

Mohr, J. W., \& Neely, B. (2009). Modeling Foucault: Dualities of power in institutional fields. Research in the Sociology of Organizations, Volume 27, 203-255. Bingley et al.: Emerald.

Newman, M. E. J. (2006). Modularity and community structure in networks. Proceedings of the National Academy of Sciences, 103(23), 8577-8582.

Ocasio, W., Loewenstein, J., \& Nigam, A. (2015). How streams of communication reproduce and change institutional logics: The role of categories. Academy of Management Review, 40(1), 28-48.

Osborne, S. P. (2010). The new public governance? Emerging perspectives on the theory and practice of public governance. London et al:: Routledge.

Pache, A. C., \& Santos, F. (2010). When worlds collide: The internal dynamics of organizational responses to conflicting institutional demands. Academy of Management Review, 35(3), 455-476.

Pache, A. C., \& Santos, F. (2013). Inside the hybrid organization: Selective coupling as a response to conflicting institutional logics. Academy of Management Journal, 56(4), 972-1001.

Padgett, J. F., \& Ansell, C. K. (1993). Robust action and the rise of the Medici, 1400-1434. American Journal of Sociology, 98(6), 1259-1319.

Padgett, J. F., \& Powell, W. W. (2012). The emergence of organizations and markets. Princeton \& Oxford: Princeton University Press.

Pollitt, C., \& Bouckaert, G. (2011). Public management reform. A comparative analysis - New Public Management, governance, and the Neo-Weberian State. Oxford: Oxford University Press. 
Polzer T., Meyer, R. E., Höllerer, M. A., \& Seiwald, J. (2016) Institutional hybridity in public sector reform: Replacement, blending, or layering of administrative paradigms. Research in the Sociology of Organizations, Volume 48B, 69-99. Bingley et al.: Emerald.

Powell, W. W., \& Colyvas, J. A. (2008). Microfoundations of institutional theory. In R. Greenwood, C. Oliver, R. Suddaby, \& K. Sahlin (Eds.), The SAGE handbook of organizational institutionalism (pp. 276-298). London, UK, Thousand Oaks et al.: SAGE Publications.

Powell, W.W. \& Oberg, A. (2017): Networks and Institutions. In: R. Greenwood, C. Oliver, T. Lawrence, \& R.E. Meyer (Eds.), The SAGE handbook of organizational institutionalism. $2^{\text {nd }}$ edition. Xxx: SAGE Publications.

Powell, W. W., Oberg, A., Korff, V., \& Kloos, K. (2017). Institutional analysis in a digital era: Mechanisms and methods to understand emerging fields. In G. Kruecken, C. Mazza, R. E. Meyer, \& P. Walgenbach (Eds.), New themes in institutional analysis: Topics and issues from European research. Cheltenham, UK: Edward Elgar.

Pratt, M. G., \& Foreman, P. O. (2000). Classifying managerial responses to multiple organizational identities. The Academy of Management Review, 25(1), 18-42.

Pratt, M. G., \& Corley, K. G. (2007). Managing multiple organizational identities: On identity ambiguity, identity conflict, and members' reactions. In C. A. Bartel, S. L. Blader \& A. Wrzesniewski (Eds.), Identity and the modern organization (pp. 99-118). Mahwah, NJ: Lawrence Erlbaum.

Pratt, M. G., \& Kraatz, M. S. (2009). E pluribus unum: Multiple identities and the organizational self. In L. M. Roberts \& J. E. Dutton (Eds.), Exploring positive identities and organizations: Building a theoretical and research foundation (pp. 377-402). New York et al.: Taylor \& Francis.

Rao, H., Monin, P., \& Durand, R. (2003). Institutional change in Toque Ville: Nouvelle cuisine as an identity movement in French gastronomy. The American Journal of Sociology, 108(4), 795-843.

Raynard, M. (2016). Deconstructing complexity: Configurations of institutional complexity and structural hybridity. Strategic Organization, 14(4), 310-335.

Reay, T., \& Jones, C. (2016). Qualitatively capturing institutional logics. Strategic Organization, 14(4), 441454.

Rhodes, R. A. (2007). Understanding governance: Ten years on. Organization Studies, 28(8), 1243-1264.

Sahlin-Andersson, K. (2001). National, international and transnational constructions of new public management. In T. Christensen \& P. Lægreid (Eds.), New public management: The transformation of ideas and practice (pp. 43-72). Aldershot: Ashgate.

Scharpf, F. W. (1997). Games real actors play: Actor-centered institutionalism in policy research. Boulder, CO: Westview.

Schedler, K., \& Proeller, I. (2009). New Public Management. Bern: Haupt.

Schedler, K., \& Ruegg-Stürm, J. (2013). Multirationales Management. Bern: Haupt.

Sillince, J. A. A., \& Brown, A. D. (2009). Multiple organizational identities and legitimacy: The rhetoric of police websites. Human Relations, 62(12), 1829-1856.

Sinha, P., Daellenbach, U., \& Bednarek, R. (2015). Legitimacy defense during post-merger integration: Between coupling and compartmentalization. Strategic Organization, 13(3), 169-199.

Smets, M., Jarzabkowski, P., Burke, G., \& Spee, P. (2015). Reinsurance trading in Lloyd's of London: Balancing conflicting-yet-complementary logics in practice. Academy of Management Journal, 58(3), 932-970.

Stryker, S. (1980). Symbolic interactionism: A social structural version. Caldwell: Blackburn

Stryker, S. (2008). From Mead to a structural symbolic interactionism and beyond. Annual Review of Sociology, 34, 15-31.

Stryker, S., \& Burke, P. J. (2000). The past, present, and future of an identity theory. Social psychology quarterly, 63(4), 284-297.

Tálos, E. (Ed.). (1998). Soziale Sicherung im Wandel. Österreich und seine Nachbarstaaten im Vergleich, Wien: Böhlau.

Thornton, P. H., \& Ocasio, W. (1999). Institutional logics and the historical contingency of power in organizations: Executive succession in the higher education publishing industry, 1958-1990. American journal of Sociology, 105(3), 801-843.

Thornton, P. H., Ocasio, W., \& Lounsbury, M. (Eds.). (2012). The institutional logics perspective: A new approach to culture, structure and process. Oxford: Oxford University Press.

Vogel, R. (2012). Framing and counter-framing new public management: The case of Germany. Public Administration, 90(2), 370-392.

Voronov, M., De Clercq, D., \& Hinings, C. B. (2013). Institutional complexity and logic engagement: An investigation of Ontario fine wine. Human Relations, 66(12), 1563-1596.

Waldorff, S. B., Reay, T., \& Goodrick, E. (2013). A tale of two countries: How different constellations of logics impact action. Research in the Sociology of Organizations, Volume 39, 99-129. Bingley et al.: Emerald. 
Whetten, D. A., \& Mackey, A. (2002). A social actor conception of organizational identity and its implications for the study of organizational reputation. Business \& Society, 41(4), 393-414.

White, H. C., Boorman, S. A., \& Breiger, R. L. (1976). Social structure from multiple networks. I. Blockmodels of roles and positions. American Journal of Sociology, 81(4), 730-780.

Zuckerman, E. (1999). The categorical imperative: Securities analysts and the illegitimacy discount. American Journal of Sociology, 104(5), 1398-1438. 


\section{APPENDIX: TABLES AND FIGURES}

\begin{tabular}{|c|c|c|}
\hline Block & Role identity of the City & Description \\
\hline 1 & The 'activating' city & $\begin{array}{l}\text { The city encourages and enables active participation in policy and decision- } \\
\text { making. As a democratic public body, it displays extensive communication } \\
\text { with its constituencies and integrates their various expectations and } \\
\text { demands. Encouragement of participation enables the city to consider and } \\
\text { serve the needs of the populace. }\end{array}$ \\
\hline 2 & The 'responsive' city & $\begin{array}{l}\text { The city reacts to the demands of its inhabitants. This entails providing } \\
\text { important and adequate information about all relevant topics and issues, as } \\
\text { well as offering adequate services that correspond to the needs of their } \\
\text { recipients. }\end{array}$ \\
\hline 3 & The 'servicing' city & $\begin{array}{l}\text { The city not only provides information and services, but is accessible and } \\
\text { available for its inhabitants. In the spirit of NPM, it shows a high degree of } \\
\text { customer-orientation by designing its services in a user-friendly way. While } \\
\text { the 'providing' city (see below) guarantees high quality services, the } \\
\text { 'servicing' city guarantees high quality processes. }\end{array}$ \\
\hline 4 & The 'context-shaping' city & $\begin{array}{l}\text { The city is also responsible for the construction and maintenance of an } \\
\text { adequate infrastructure and functioning within a broader 'context' for city } \\
\text { life. Enacting this role identity, it creates utilities and safeguards amenities } \\
\text { for its inhabitants. Infrastructure can be both material and immaterial. }\end{array}$ \\
\hline 5 & The 'advocating' city & $\begin{array}{l}\text { The city takes on the role of a legal representative of some of its } \\
\text { inhabitants, consulting them in various issues, conferring and guaranteeing } \\
\text { rights, and preventing negative conditions. In this sense, it also actively } \\
\text { takes a stand and speaks up for parts of the populace. }\end{array}$ \\
\hline 6 & The 'providing' city & $\begin{array}{l}\text { The city is an important provider of goods and services, but also of an } \\
\text { adequate quality of living in general. Its inhabitants are, to a certain degree, } \\
\text { dependent on these benefits the city makes available. Insofar, the city } \\
\text { improves - in return for paying taxes and complying with the rules and } \\
\text { norms of city life - the everyday quality of life for its populace. }\end{array}$ \\
\hline 7 & The 'enabling' city & $\begin{array}{l}\text { The city aims at improving conditions especially for its weaker inhabitants. } \\
\text { However, it not only supports them financially and structurally: It also aims } \\
\text { at capacity building by enabling its inhabitants to develop their knowledge, } \\
\text { skills and autonomy, thus increasing their chances of a better life. }\end{array}$ \\
\hline 8 & The 'regulating' city & $\begin{array}{l}\text { The city is also responsible for law and order. Enacting this role identity, it } \\
\text { has to constrain the possible actions of its inhabitants through regulation in } \\
\text { order to protect themselves as well as the public welfare. At the same time, } \\
\text { it enables actions within the confines of these rules and norms. }\end{array}$ \\
\hline 9 & The 'steering/controlling' city & $\begin{array}{l}\text { The city also controls its inhabitants more directly. In specific relationships, } \\
\text { it is empowered to demand actions - or their omittance - from its } \\
\text { inhabitants. Some city agencies may also directly intervene in the everyday } \\
\text { life of its populace. Finally, divergent aims and objectives may also call for } \\
\text { coordination. }\end{array}$ \\
\hline 10 & The 'balancing' city & $\begin{array}{l}\text { The city assumes particular responsibility for the weakest among its } \\
\text { constituency. This means, on the one hand, requesting considerateness from } \\
\text { those who are better off, and, on the other, compensating those who are or } \\
\text { were wronged and are not able to stand up for themselves. }\end{array}$ \\
\hline
\end{tabular}

Table 1: Action blocks and role identities of the city 


\begin{tabular}{lll}
\hline Block & Constituents' (counter-)role & Description \\
\hline 11 & Local participants & $\begin{array}{l}\text { Local participants are primarily defined through their active involvement in } \\
\text { city policy and decision-making. They are the primary users of public } \\
\text { space and possess an intrinsic interest in making the city as attractive as } \\
\text { possible as a space of living. As local participants are at the very core of } \\
\text { the city's constituency, the city assumes a multiplicity of role identities } \\
\text { towards them. }\end{array}$
\end{tabular}

12 Users of infrastructure

Rechtssubjekte

Citizens/sovereigns

\section{Inhabitants}

Customers
The users of infrastructure are positioned in a similar way as the local participants. However, they are more specific in their claims towards the city, focusing mostly on housing, the traffic system, and the educational infrastructure. While they also impact policy and decision-making, they are not necessarily inhabitants of the city, but also include, for instance, commuters and visitors.

The Rechtssubjekte are an abstract and formal category that is strongly defined through its particular rights and obligations. They are equally represented as they are controlled by the city, making information a third primary focus of treatment. This category contains groups that enter a specific (mostly legal) relationship with the city.

The citizens as sovereigns are similar to the local participants in that they actively take part in the political and democratic process. However, as opposed to the local participants, the citizens are more ambiguous in their relationship to the city, as they are more strongly subjected to ideas of service provision and 'customer orientation'. Essentially, the citizens are a very comprehensive category that is the target of almost every type of action the city has to offer.

The objects of canvassing encompass a number of stakeholders that are politically important and, therefore, need to be treated with particular care. Primarily, these are the Viennese, a label that implies a strong identification with the city. They are characterized as recipients of benefits but - as constituents of the city - are also reminded of their obligations and responsibilities towards the city itself and the weaker members of society.

The city's inhabitants are a rather generic group sharing certain characteristics with the local participants and the citizens as sovereigns. They utilize infrastructure and services, but, interestingly, rarely voice demands against the city actively, making them a rather passive category.

The customers are rather negligible from a governance and political point of view. However, they consume - and, consequently, evaluate - the city's goods and services, implying negotiating power. In the spirit of customer orientation, they are also granted access to information relevant to them.

The people in need encompass a diverse group of stakeholders that all share their strong dependence on the city's support. In order to be eligible for this support, they are subjected to a specific set of regulations, but also possess a limited capacity for participation.

The entrusted are the most passive stakeholder block and, thus, completely dependent on the city: on direct support as well as on the representation of their interests.

The policy targets are specific in that they are, on the one hand, dependent on the city's support in different ways and degrees, but, on the other, highly relevant as voters, either now or in the near future. They include, for instance, women, girls, pupils, and trainees. Because of their potential political relevance, they are not only supported, but also developed and informed, in order to nurture them to become responsible and productive citizens. 


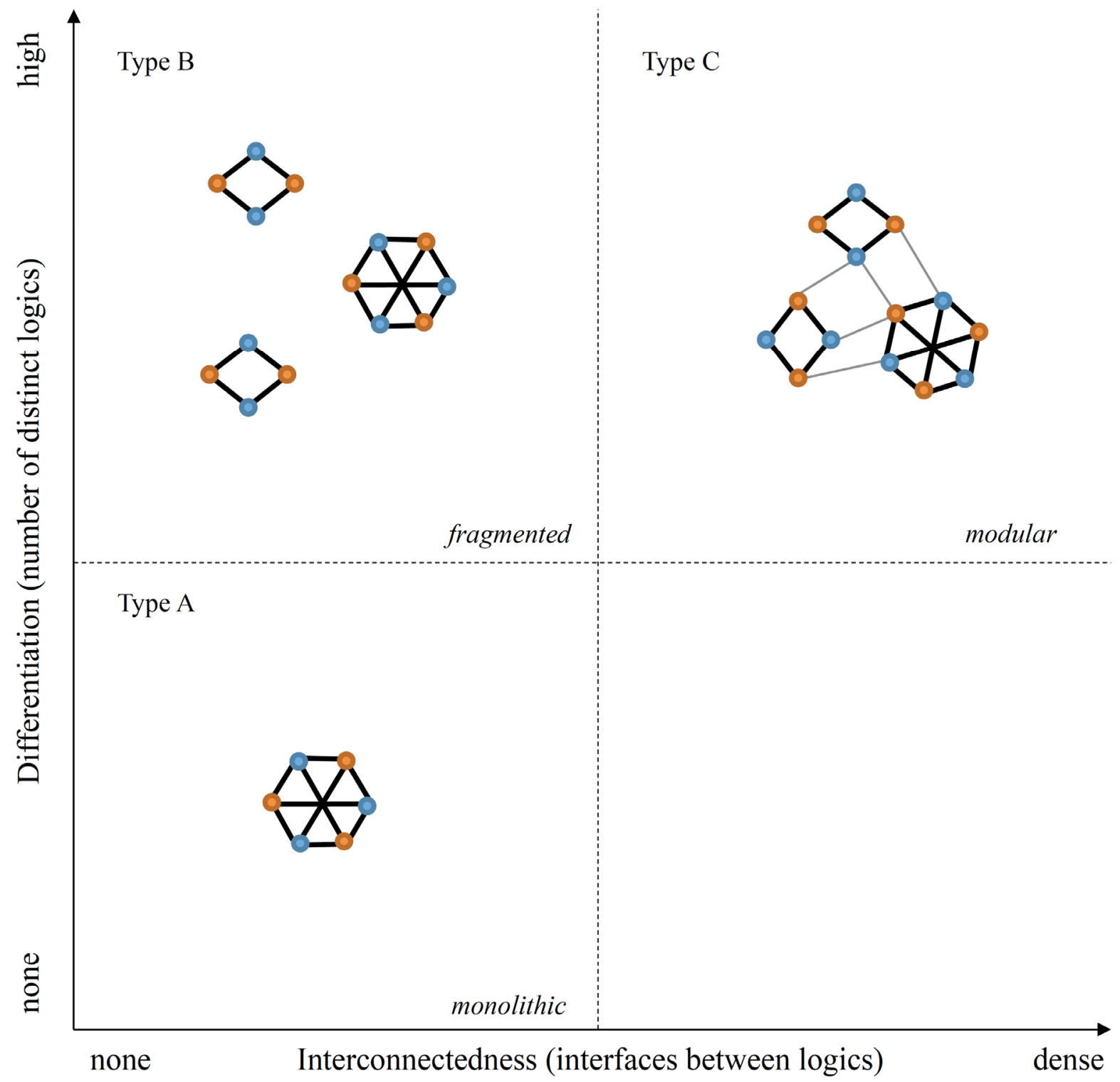

Figure 1: Different forms of pluralism 


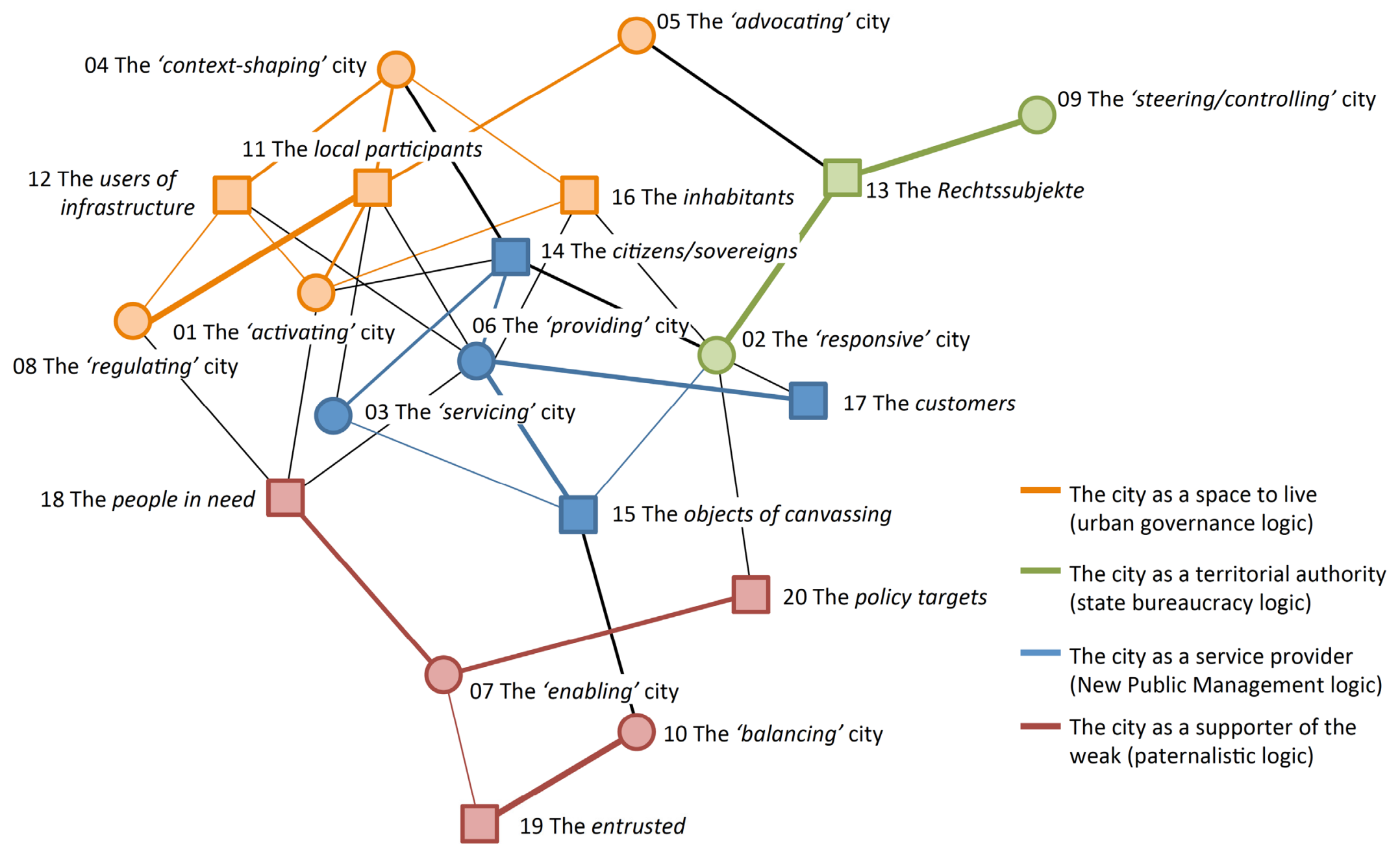

Figure 2: The City of Vienna as a nexus of role identities 


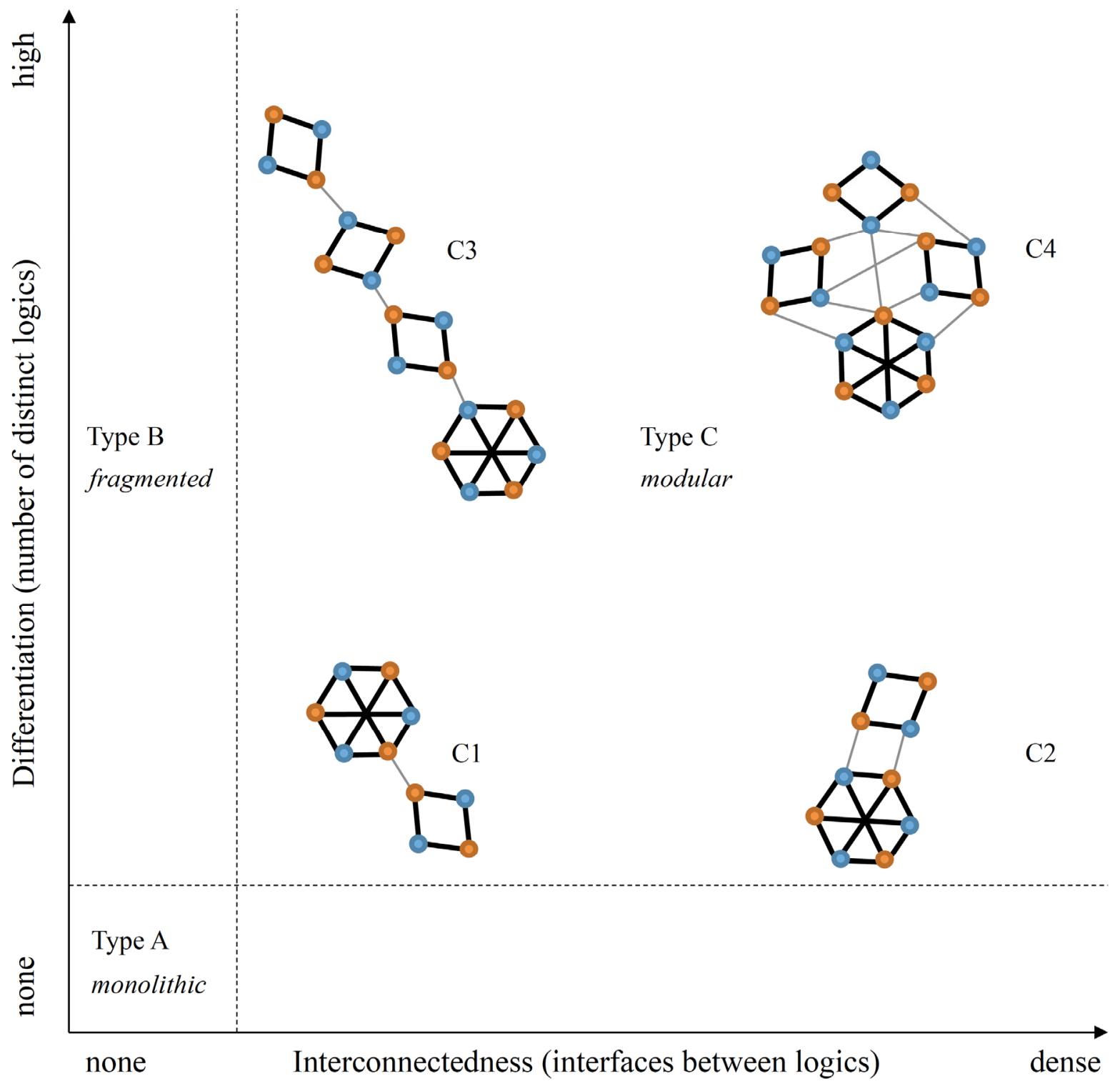

Figure 3: Variants of the modular form 